\title{
Ciência em publicidades: uma análise das emissoras televisivas de maior audiência no Brasil
}

University radios in a convergence scenario: thoughts about the professional formation and the university role

Science in advertising: an analysis of the most watched television stations in Brazil

Vanessa Brasil DE CARVALHO, Brasil

Universidade Federal do Rio de Janeiro / vanessabrasilcarvalho@gmail.com

Luisa MASSARANI, Brasil

Instituto Nacional de Comunicação Pública da Ciência e Tecnologia /

luisa.massarani5@gmail.com

Chasqui. Revista Latinoamericana de Comunicación

N. ${ }^{\circ} 140$, abril - julio 2019 (Sección Ensayo, pp. 297-314)

ISSN 1390-1079 / e-ISSN 1390-924X

Ecuador: CIESPAL

Recibido: 29-03-2018 / Aprobado: 16-07-2019 


\section{Resumo}

Neste artigo, analisamos publicidades veiculadas pelas duas emissoras de TV aberta brasileira de maior audiência (TV Globo e TV Record) que apresentaram questões relacionadas à ciência em suas narrativas. As peças foram submetidas a um protocolo de análise de conteúdo e processadas pelo software de análise de modelos mistos, o QDAMiner. Nossos resultados mostram que TV Record transmitiu mais publicidades com abordagem científica que a TV Globo e houve ênfase em assuntos da saúde e de estética. A ciência foi utilizada como forma de legitimar os produtos e as marcas, de maneira a contribuir para o convencimento dos telespectadores.

Palavras-chave: Ciência na TV; TV brasileira; Publicidade; TV Globo; TV Record

\section{Abstract}

In this paper, we analysed advertisements broadcast by the two highest audience Brazilian TV channels (TV Globo and TV Record), which presented issues related to science in their narratives. The advertisements were analysed using a content analysis protocol and processed by mixed analysis QDAMiner software. Our results show that TV Record vehiculated more advertisements with scientific approach than TV Globo and health and aesthetic issues were the most frequent subjects. Science was used as a way to legitimize products and brands, in order to contribute to convincing viewers.

Keywords: Science on TV; Brazilian TV; Advertising; TV Globo; TV Record

\section{Resumen}

En este artículo, analizamos publicidades de las dos emisoras de televisión abierta brasileña de mayor audiencia (TV Globo y TV Record) que presentaron cuestiones relacionadas a la ciencia en sus narrativas. Las piezas fueron sometidas a un protocolo de análisis de contenido y procesadas por el software de análisis de modelos mixtos, el QDAMiner. Nuestros resultados muestran que TV Record transmitió más publicidad con enfoque científico que la TV Globo y hubo énfasis en asuntos de salud y de estética. La ciencia fue utilizada como forma de legitimar los productos y las marcas, de manera a contribuir al convencimiento de los telespectadores.

Palabras claves: Ciencia en la TV; TV brasileña; publicidad; TV Globo; TV Record 


\section{Introdução}

De acordo com Cashmore (1998, p. 94), "a televisão é propaganda". Para o autor, a propaganda tem um papel importante para construir e cultivar o mercado consumidor e, a partir da criação da televisão, na metade do século XX, esse papel vem se consolidando.

No Brasil, a TV caracterizou-se como um veículo publicitário desde os seus primeiros anos, seguindo o modelo comercial norte-americano e transformando-se no meio preferido das agências de publicidade em razão do seu grande potencial de audiência. Dessa forma, o desenvolvimento da televisão no país está diretamente relacionado aos investimentos publicitários, que são sua maior fonte de receita até os dias de hoje (Mattos, 2010).

Em 2016, tais investimentos somaram quase $\mathrm{R} \$ 72$ milhões para a TV aberta - o que representa $55,1 \%$ do total de investimentos em todas as mídias no país (Kantar Ibope Mídia, 2016). Desde 2010, o percentual de investimentos na TV aberta varia de $53 \%$ a $56 \%$ (Mídia Dados Brasil, 2017), o que mostra um cenário estável.

Esses dados mostram a estreita relação entre publicidade e televisão no Brasil, país no qual a TV possui uma importância social e cultural de extrema relevância (Reimão, 2000; Wolton, 2006), estando presente em $97,1 \%$ dos domicílios brasileiros (IBGE, 2016).

Apesar disso, os estudos sobre publicidade e televisão ainda são pouco frequentes na área de comunicação (Jacks \& Piedras, 2006; Jacks; Menezes \& Piedras, 2008; Piedras, 2014). Alguns dos estudos existentes ou são de outras áreas do conhecimento ou se voltam para tipos específicos de publicidades como, por exemplo, sobre medicamentos (Azevedo \& Pereira, 2010; Wzorek, 2005), alimentos (Almeida, Nascimento \& Quaioti, 2002; Fialho \& Almeida, 2008) e produtos cosméticos (Haberkamp, 2013; Lucas \& Hoff, 2007; MELO et al., 2005).

Lucas \& Hoff $(2006,2007)$ destacam que a publicidade brasileira referente a medicamentos e cosméticos se caracteriza por uma abordagem de conteúdos de ciência e tecnologia. Os autores observam uma progressiva "cientificização do discurso publicitário", de maneira que palavras do cotidiano passam a ser atreladas a termos científicos com maior regularidade.

Para Ferreira (2009), a presença da ciência em publicidades veicula um discurso de incontestabilidade. Para o autor, citar o nome do composto químico de um produto daria mais credibilidade à informação, uma vez que esta seria sustentada por um "prova científica". Isso também foi observado em outros estudos, como os de Rosa (2005), Torres (2012) e Carmo (2014).

Nesse estudo, nosso objetivo é analisar as publicidades televisivas veiculadas no Brasil que apresentam conteúdos científicos em suas narrativas, sem delimitar a análise a um determinado tipo de produto, como as pesquisa citadas acima. 
Este artigo apresenta desdobramentos dos resultados de um projeto mais amplo sobre a cobertura da ciência na TV brasileira. ${ }^{1}$ Nossos resultados iniciais mostraram que as publicidades foram a categoria televisiva - utilizando a nomenclatura de Aronchi (2004) - que fez uso de conteúdos científicos com maior frequência, se comparada com as programações de entretenimento, informação e educação. Neste trabalho, nossa intenção é analisar essas peças publicitárias, ${ }^{2}$ identificando suas principais características e refletir sobre a ciência presente nessas peças.

\section{Metodologia}

Considerando que o foco de nosso estudo é a TV aberta brasileira, selecionamos para análise as duas emissoras de maior audiência no Brasil: TV Globo e TV Record (Mídia Dados Brasil, 2017). A TV Globo foi criada em 1965, na cidade do Rio de Janeiro, pelo jornalista Roberto Marinho, dono do jornal impresso O Globo. É líder de audiência da TV aberta brasileira desde a década de 1970 (Bolaño, 2004; Mattos, 2010), sendo a maior rede de televisão do Brasil, e seu sinal chega a 5.476 municípios, representando 98,3\% da população do país (Mídia Dados Brasil, 2017). O Grupo Globo, proprietário da emissora e pertencente à família do seu fundador, atua ainda em outros ramos da comunicação, como jornais, revistas, emissoras de rádio, TV por assinatura, empresas de distribuição de conteúdo e informação (Grupo Globo, 2017; Mattos, 2010).

A TV Record foi criada em 1953 pelo empresário Paulo Machado de Carvalho, na cidade de São Paulo. Foi a segunda emissora a entrar no ar no Brasil, após a pioneira TV Tupi, de Assis Chateaubriand, e é a mais antiga ainda em atividade (Bolaño, 2004; Mattos, 2010; Rede Record, 1998). Foi vice-líder da audiência entre os anos de 2007 a 2013, mantendo-se, atualmente, entre as três maiores redes nacionais de televisão. Seu sinal está disponível para 78,1\% da população brasileira em todos os estados, chegando a 4.351 municípios (Midia Dados Brasil, 2017).

Para selecionar as peças publicitárias analisadas, escolhemos uma amostra de duas semanas construídas, em um total de 14 dias, representativos de um período de seis meses de 2013 (junho a novembro). Para compor as semanas construídas, sorteamos aleatoriamente, no período considerado, duas segundasfeiras, duas terças-feiras, duas quartas-feiras, e assim sucessivamente, até termos duas vezes cada dia da semana.

1 Este estudo integra um projeto mais amplo, apoiado pelo Conselho Nacional de Desenvolvimento Científico e Tecnológico (CNPq) e pela Fundação de Amparo à Pesquisa do Estado do Rio de Janeiro (Faperj). Foi desenvolvido por meio da colaboração de quatro instituições brasileiras (Fundação Oswaldo Cruz, Universidade de São Paulo e Universidades Federais do Pará e de Minas Gerais), do qual apresentamos um recorte referente aos dados coletados no Rio de Janeiro pela Fundação Oswaldo Cruz.

2 Neste artigo, adotamos a nomenclatura de "publicidades" ou "peças publicitárias" para identificar todos os itens da categoria televisiva "publicidade", classificados por Aronchi (2004), registrados na programação diária das duas emissoras analisadas. 
Durante esses dias, gravamos e assistimos na íntegra toda a programação veiculada pelas duas emissoras, totalizando 672 horas. Os dias sorteados foram: domingo (22 e 29 de setembro), segunda-feira (19 de agosto e 16 de setembro (segunda-feira), terça-feira (18 de junho e 29 de outubro), quarta-feira (18 de setembro e 13 de novembro), quinta-feira (12 de setembro e 24 de outubro), sextafeira (4 de outubro e 29 de novembro) e sábado (31 de agosto e 14 de setembro).

Para selecionar as peças que seriam analisadas desenvolvemos quatro critérios, tendo como base o protocolo da Rede Ibero-americana de Monitoramento e Capacitação em Jornalismo Científico (Autor \& Ramalho), associado a Rondelli (2004) e Trench (2003). Para que a programação fosse incluída em nosso corpus, esta deveria apresentar pelo menos um desses critérios - mas também poderia apresentar mais de um ou todos.

A menção direta à ciência e/ou à tecnologia é o primeiro critério, que engloba peças nas quais são citadas as palavras ciência, tecnologia, cientista(s), pesquisa(s), pesquisador(es), instituições de pesquisa e universidades - desde que relacionadas à produção científica. Também consideramos a menção a métodos ou processos científicos, apresentação de resultados de pesquisas ou produtos desenvolvidos cientificamente, assuntos relacionados à política de C\&T e peças que apresentavam um cientista/pesquisador, desde que identificado dessa maneira.

O segundo critério compreende a menção a dados ou termos científicos, que seriam aquelas informações atribuídas à comunidade científica ou a um determinado ramo do conhecimento, mesmo que não sejam proferidos por cientistas. Ou seja, são dados ou reflexões que não se encaixam no vocabulário do cotidiano, no senso comum, sendo, portanto, atribuídos à pesquisa científica.

As programações que apresentassem algum tipo de ilustração e/ou animação contendo informações científicas ou baseadas nelas foram incluídas no corpus, de acordo com o terceiro critério. Essas imagens poderiam representar a explicação de um fato, um procedimento científico ou um exemplo da realidade. Por fim, o quarto critério incluiu peças de divulgação científica: àquelas voltadas para o público amplo e/ou leigo com temáticas científicas e/ou voltadas para a popularização da ciência.

Após essa seleção, a programação foi analisada a partir de um protocolo de análise de conteúdo, também construído com base na ferramenta desenvolvida pela Rede Ibero-americana de Monitoramento e Capacitação em Jornalismo Científico.

Os critérios e o protocolo foram desenvolvidos visando analisar programações das diferentes categorias televisivas, ou seja, peças encontradas em filmes, desenhos animados, séries, telenovelas, programas educativos, programas de variedades, telejornais e publicidades. Contudo, este artigo concentra-se na análise apenas da última categoria. Tomamos como base a categorização feita por Aronchi (2004) sobre os gêneros e categorias televisivas 
brasileiras, que identificou cinco categorias: entretenimento, informação, educação, publicidade e outros.

Para o autor, a categoria de publicidade é representada por quatro gêneros: filme comercial, chamada de patrocínio ou merchandising, político, sorteio e telecompra. $\mathrm{O}$ gênero mais comum na televisão brasileira dessa categoria é o filme comercial. Este é o tradicional minifilme - de 30 segundos, normalmente que é transmitido nos intervalos das programações da grade televisiva, repetidas vezes ao longo do dia.

A chamada de patrocínio ou merchandising éo momento publicitário inserido nos próprios programas da grade das emissoras - programas de variedades, principalmente - com ou sem a intervenção do apresentador. A propaganda política - no período eleitoral ou fora dele - representa o gênero política e os programas com sorteios - como os do Programa Silvio Santos - caracterizam o gênero sorteio. Já a telecompra é uma programação de venda de produtos pela TV. Além desses, incluímos o gênero "chamadas" para aquelas programações que anunciam outras programações - como, por exemplo, chamadas de telenovelas ou telejornais ao longo do dia, que oferecem informações antecipadas sobre a programação que será transmitida horas depois.

Neste estudo, todas as publicidades identificadas foram transcritas para operacionalizar uma análise mista - quantitativa e qualitativa - por meio da utilização do software QDA Miner, da Provalis research. Esse software possibilita tratar os dados via Computer Aided Qualitative Data Analysys (CAQDAS), de maneira a associar análise de conteúdo e análises lexicográficas disponibilizadas pelo programa (Lewis \& Maas, 2007).

\section{Resultados}

\subsection{Marcas, produtos e principais temas das publicidades relacionadas à ciência}

Ao todo, identificamos nas 88 peças de publicidade que abordaram questões científicas, em um total de 843 inserções na programação analisada, sendo a categoria televisiva que veiculou com maior frequência tais temas. A TV Record foi a emissora que veiculou mais publicidades relacionadas a temáticas científicas, totalizando $76,2 \%$ das peças do nosso corpus. A TV Globo, por sua vez, registrou apenas 201 inserções de publicidades que abordaram assuntos da ciência, representando $23,8 \%$ do corpus.

A maioria das peças apresentou o critério de inclusão no corpus caracterizado como menção a dados e termos científicos (95,3\% das publicidades). Ilustrações e/ou animações relacionadas à ciência foram o segundo critério de inclusão mais mencionado $(70,1 \%)$ - sendo que uma mesma publicidade poderia estar 
associada a vários critérios, por isso a soma é superior a 100\%. A menção direta à ciência, contudo, foi menos frequente (21,2\%).

A menção a dados ou termos científicos pode ser exemplificada pela publicidade do medicamento Asepxia Gel 10\% que diz:

Asepxia desenvolveu um novo medicamento: Asepxia Gel 10\%. O ativo de Asepxia Gel 10\% elimina a bactéria $P$. acnes, que está entre os principais causadores da acne. Enquanto age, os grânulos antibacterianos de peróxido de benzoíla penetram profundamente na pele para combater e eliminar a acne. Resultados comprovados já no segundo dia de tratamento. Nada melhor que um medicamento. Asepxia Gel 10\% (Asepxia Gel, TV Record, 19 ago 2013).

Como podemos ver, esta publicidade faz uso de termos científicos - bactéria P. acnes e grânulos antibacterianos de peróxido de benzoíla - para explicar a ação do medicamento, incentivar e justificar a escolha por esse produto.

Dentro do critério de presença de ilustrações e/ou animações relacionadas à ciência, consideramos programações que mostraram recursos gráficos e efeitos visuais para representar um procedimento científico ou, no caso das publicidades mais especificamente, a ação do produto ofertado no organismo humano - como acontece na peça do produto Cicatricure creme, veiculado pela TV Record.

Veja algumas imagens da peça:

Figura 1 - Ilustrações da publicidade do produto Cicatricure creme

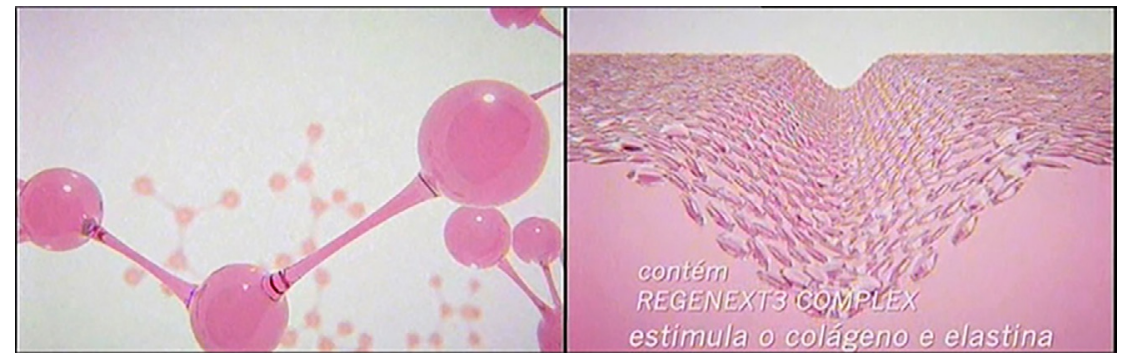

Fonte: TV Record, 19 ago 2013.

Já a menção direta à ciência pôde ser verificada pela citação de estudos científicos ou pela própria presença de um cientista. Como exemplo do primeiro caso, temos o comercial do produto Advil que afirma: "Advil age no foco das dores de cabeça, nas costas e musculares. Estudo clínico demonstrou que Advil é ainda mais rápido, agindo a partir de 10 minutos. Tudo isso com apenas uma cápsula” (Advil, TV Globo, 12 ser 2013). 
O exemplo para o segundo caso é a presença de um "pesquisador R\&D" (identificado dessa forma, grifo nosso) na publicidade sobre o hidratante da marca Goicoechea, veiculada pela TV Record (Imagem 2, à esquerda), e de dois pesquisadores na propaganda sobre um automóvel da marca Chevrolet, veiculada pela TV Globo (Imagem 2, à esquerda).

Figura 2 - Cientistas em publicidades das marcas Goicoechea (à esquerda) e Chevrolet (à direta)

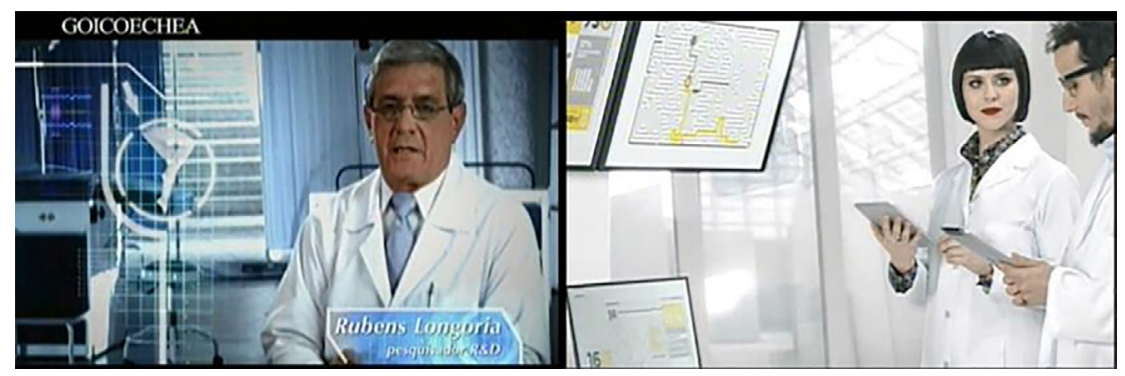

Fonte: TV Record, 13 nov 2013; TV Globo, 24 out 2013

Não observamos uma variação importante na presença de publicidades com conteúdos científicos ao longo do dia, apesar de notarmos um ligeiro aumento da quantidade delas durante a tarde $(29,7 \%)$ e a noite $(26,5 \%) .{ }^{3}$ Os domingos foram os dias nos quais foi veiculada a menor quantidade de peças publicitárias (10,2\%), enquanto que as terças-feiras temos um aumento de transmissão (17,4\%).

Veja no quadro 1, as marcas e os produtos mais frequentes em nosso material.

Quadro 1 - Marcas e produtos relacionados à ciência mais recorrentes no período analisado

\begin{tabular}{|l|c|c|}
\hline \multicolumn{1}{|c|}{ Marcas/produtos } & Frequência & Porcentagem \\
\hline Asepxia & 158 & $18,7 \%$ \\
\hline Cicatricure & 154 & $18,2 \%$ \\
\hline Goicoechea & 99 & $11,7 \%$ \\
\hline Danone & 58 & $6,9 \%$ \\
\hline Colgate & 53 & $6,2 \%$ \\
\hline Pointts & 43 & $5,1 \%$ \\
\hline Tio Nacho & 35 & $4,1 \%$ \\
\hline L'Oréal Paris & 21 & $2,5 \%$ \\
\hline Canal Futura & 20 & $2,4 \%$ \\
\hline
\end{tabular}

Em relação aos gêneros da categoria publicidade, encontramos peças representantes dos gêneros chamadas $(1,1 \%)$, sorteio $(2,7 \%$ do corpus),

3 Durante a madrugada, registramos $19,1 \%$ das peças publicitárias e, pela manhã, $24,8 \%$. 
merchandisings $(2,7 \%)$ e filmes comerciais $(96,0 \%)$, como será mais detalhado a seguir.

As chamadas estiveram presentes apenas na TV Globo e faziam referência a programações da própria emissora. Identificamos duas chamadas da telenovela Amor à Vida,${ }^{4}$ que apresentava uma discussão sobre um resultado de DNA que traria a confirmação da maternidade de uma das personagens principais da telenovela; uma do telejornal Bom dia Brasil ${ }^{5}$ sobre uma pesquisa que revelou deficiência de vitamina D em crianças no Sul do país; seis do Globo Repórter, ${ }^{6}$ que veiculou chamadas diferenciadas - quatro sobre vida após a morte e duas sobre medicina oriental.

O gênero sorteio foi identificado na publicidade sobre um aplicativo de celular chamado "Sorte em Dobro", que oferece informações "curiosas" àqueles que quiserem comprar o aplicativo. A peça apresenta uma narrativa no formato de "O que é? o que é?", com alguns dados científicos e ainda imagens para ilustrar essas informações. Identificamos 23 peças do gênero merchandising, sendo que 22 delas foram veiculadas pela TV Record. As marcas e produtos que fizeram uso desse gênero foram: Drena Corpus, Imecap hair, Lipomax, Pantene, Super Cálcio $D$, Varicell e Vital 50o. As demais peças publicitárias foram classificadas como filme comercial: 809 peças ou $96,0 \%$ do nosso corpus.

As áreas do conhecimento identificadas nas peças ficaram concentradas nas Ciências Biológicas (55,9\%) e nas Ciências da Saúde (40,2\%). As Engenharias e Tecnologias representaram 2,6\% das publicidades identificadas e as demais áreas não ultrapassaram $2 \%$ do corpus, cada uma. As palavras chave conferidas a todas as peças nos mostram uma relação com as áreas do conhecimento: as mais frequentes possuem relação com as áreas de ciências biológicas e da saúde. Veja no gráfico 1 as palavras chave mais frequentes.

Figura 3 - Porcentagem da presença das palavras-chave mais frequentes no corpus

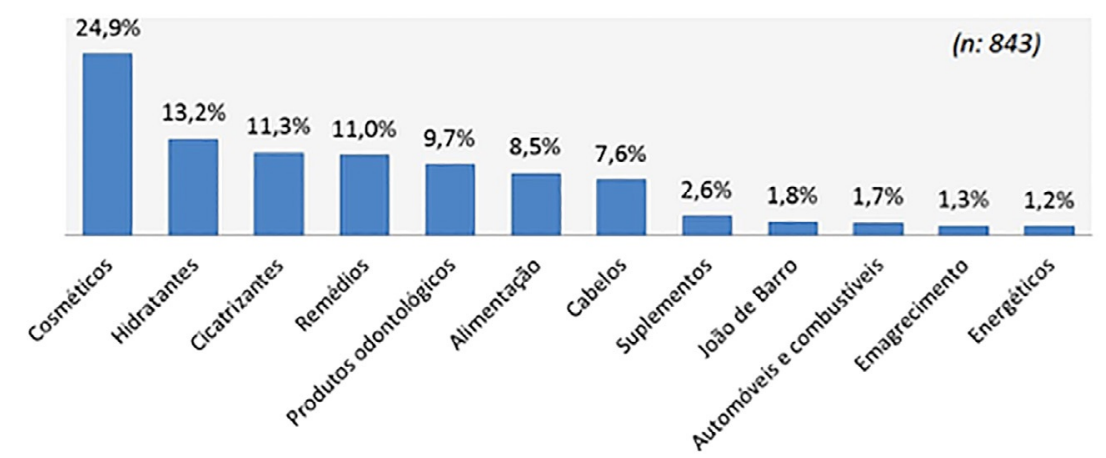

Telenovela veiculada na faixa das 21h, de segunda-feira ao sábado, entre maio de 2013 a janeiro de 2014 Veiculado de segunda à sexta-feira às $7 \mathrm{~h} 30$.

Programa informativo semanal veiculado às sextas-feiras, às $22 \mathrm{~h}$. 
As publicidades sobre cosméticos, hidratantes e cicatrizantes foram as três mais recorrentes em todo o nosso material, sendo que as peças sobre cabelos também podem ser associadas às três primeiras por se enquadrarem no assunto de "estética". Nesse grupo, algumas marcas que se destacaram são Asepxia, Goicoechea, Cicatricure, Tio Nacho e L'Óreal Paris.

Os remédios vêm logo em seguida, representando um grupo de publicidades importante, marcado pelos produtos Pointts, Tylenol, Advil e Salompas. Os produtos odontológicos também foram bastante frequentes, em especial àqueles das marcas Colgate e Sensodyne.

Os produtos relacionados à alimentação são, principalmente, das marcas Danone e Yakult. Já dentre os suplementos alimentares e energéticos, destacamos os produtos Centrum e Targifor. Também relacionado a esse grupo, podemos destacar as publicidades voltadas para produtos que ajudam a manter a dieta ou a emagrecer, a exemplo de do Drena Corpus, Nutrilipo e Lipomax.

o Canal Futura apresentou publicidades com conteúdos científicos ao divulgar o canal da Fundação Roberto Marinho; entre elas, a que descrevia a espécie de ave chamada comumente de João-de-Barro se destacou.

A área de Engenharias esteve representada por publicidades sobre automóveis (principalmente das marcas Fiat, Ford e Chevrolet), combustíveis (Shell) e tecnologias para pneus (Dunlop).

Observamos ainda uma ênfase aos aspectos positivos da ciência identificados nas categorias de análise sobre benefícios $(94,7 \%)$ e promessas $(95,0 \%)$. Um exemplo desses pontos positivos pode ser visto na publicidade do produto Cetrum Select, no qual um narrador que diz:

Anos atrás meu médico sugeriu que eu tomasse Centrum Select todos os dias. Ele é formulado para pessoas com mais de cinquenta anos, tem doses extras de antioxidantes e ajuda a manter a energia e a disposição. Aí eu li um estudo que comprovou: o uso contínuo de multivitamínicos traz sim benefícios a longo prazo para a minha saúde. E a marca utilizada no estudo foi Centrum, a mesma que eu tomo (Centrum, TV Globo, 16 set 2013).

Essas características positivas só não estiveram presentes nas peças dos gêneros chamada e sorteio, em publicidades institucionais (Canal Futura, Shell, Petrobrás) e naquelas que organizaram sua narrativa por um viés mais cômico a exemplo da publicidade do automóvel Punto da marca Fiat.7

Também foram frequentes recomendações (presentes em 96,2\% das publicidades analisadas) e contextualização (81,9\%), ambas presentes na publicidade do produto Tio Nacho, que segue:

1857. Dom Inácio Corcuera cria um xampu com a extraordinária capacidade de penetrar no folículo capilar: Xampu Tio Nacho. Esse fato se tornou um dos

7 Essa publicidade continha uma sátira da primeira apresentação da luz elétrica ao público, quando Thomas Edison teria feito a experiência na frente de diversas pessoas. 
mais premiados do século XX. 2006. Estados Unidos descobrem a fórmula mais eficaz para retardar o envelhecimento capilar à base de geleia real. Agora, ambas tecnologias se juntam para criar um xampu extremamente efetivo, que atrasa o aparecimento de cabelos brancos e evita a queda por seus ingredientes naturais. Apresentamos no Brasil a reformulação do novo xampu anti-idade Tio Nacho. Detenha os cabelos brancos, detenha a queda. Tio Nacho, o rei da geleia real" (Tio Nacho, TV Record, 18 jun 2013).

Os esclarecimentos de dados ou termos científicos $(68,4 \%)$ também foram recorrentes, ainda que em menor número. Esse resultado é importante uma vez que registramos que o critério de menção a dados e termos científicos estava em 95,3\% das publicidades, ou seja, muitos termos foram citados, mas vários deles sem que fosse adicionada uma explicação.

Os cientistas estiveram presentes em apenas 28 peças, que somam 14 minutos. Eram 39 homens e 15 mulheres cientistas. Eles estavam mais presentes em peças da área de Engenharias (14 peças) e Ciências da Saúde (12 peças). As publicidades com esses personagens eram sobre tecnologias para automóveis (Chevrolet, Fiat e Ford), remédios para acne (Asepxia), hidratantes (Goicoechea) e sobre o Prêmio Jovem Cientista, do Governo Federal.

\subsection{A narrativa das publicidades}

Paralelamente à análise de conteúdo, desenvolvemos uma análise mista (qualitativa e quantitativa) das publicidades por meio da utilização do software QDA Miner, da Provalis Research. Para tanto, transcrevemos todas as peças publicitárias, totalizando 88 itens diferentes. Ou seja, essas 88 publicidades foram repetidas diversas vezes ao longo do período analisado e somam 843 peças - que foram descritas no tópico anterior.

Um dos resultados obtidos por meio desse software é visualização da frequência das palavras nas 88 peças identificadas, como podemos observar na imagem 3 .

Figura 4 - Palavras mais frequentes nas publicidades analisadas relacionadas à presença em cada peça

NOVO PELE AGORA CABELO dOR CREME ESPINHA MUITO ELIMINAR CIÊNCIA PERna RÁPIDO AGIR MELHOR SABONETE VIDA DENTISTA verauga AJUDA CRAVO gEL IDADE SAÚdE TECNOLOGIA ÚNICO CALCIO MUDAR unOURGG VITAMINA CASA FILHO RUGA SABER

Fonte: Imagem gerada pelo software QDAMiner.

Na contagem de palavras de palavras que gerou a Imagem 3 , foram excluídos pronomes, advérbios, artigos e palavras comuns da língua portuguesa, de 
maneira que estão visíveis apenas as palavras com significância para este estudo e que foram repetidas, pelo menos, 10 vezes.

Como resultado, na imagem 3 , temos as palavras que foram mais frequentemente utilizadas nas publicidades em ordem decrescente, ou seja, as palavras "novo", "pele", "agora" e "cabelo" foram as mais repetidas - 40, 32, 28 e 26 vezes respectivamente. $O$ tamanho e a cor em que estão apresentadas reflete a quantidade de peças nas quais estiveram presentes. Por exemplo, "novo" esteve em um maior número de peças publicitárias: 29 das 88 peças; "pele" em 20 peças; "muito" em 18; "agora" em 17; e "ciência" em 16.

Outra análise possível por meio do software QDAMiner é a visualização das palavras que foram utilizadas conjuntamente, criando um mapa conceitual como vemos na imagem 4.

Figura 5 - Mapa conceitual das palavras mais citadas nas publicidades analisadas e relacionadas a conotações emocionais

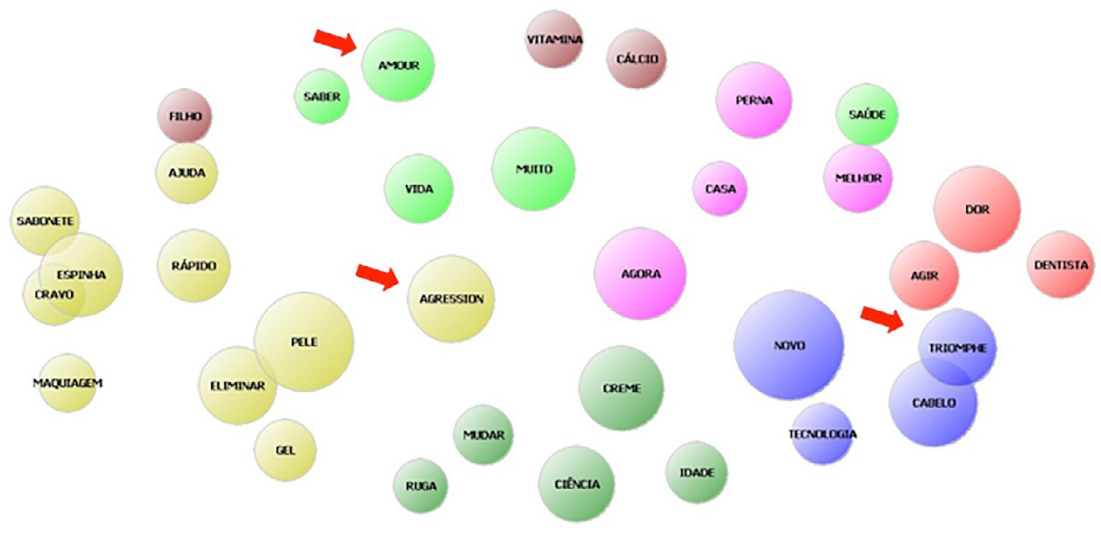

Fonte: Imagem gerada pelo software QDAMiner, apresentando nove clusters.

Nesse mapa, cada ponto representa uma palavra - novamente, foram consideradas apenas aquelas repetidas 10 vezes, no mínimo - e o tamanho de cada um está de acordo com a quantidade de vezes que cada palavra foi repetida, de maneira que "novo", "pele", "agora", "cabelo", "dor" e "creme" são os maiores pontos e os termos mais frequentes nas 88 peças de publicidades que compõem nosso corpus.

8 Foi criado um grupo de palavras intitulado "ciência" com objetivo de contabilizar de forma conjunta as diferentes as palavras relativas ao tema. Dessa forma, tem-se por "ciência" as menções a: ciência, cientista(s), científico, cientificamente, pesquisa, pesquisador(a), pesquisadores, estudo clínico e clinicamente e/ou quimicamente comprovado. 
A proximidade entre os pontos reflete as vezes nas quais tais palavras foram utilizadas em uma mesma peça publicitária. As cores também contribuem para a visualização do agrupamento de palavras que apareceram juntas. Dessa forma, podemos observar que os produtos para cabelos destacaram suas inovações e diferentes tecnologias utilizadas no seu desenvolvimento e que os produtos odontológicos, recomendados pelos dentistas, agiam para aliviar a dor.

Também foi possível relacionar as transcrições das publicidades com termos de conotação emocional disponibilizados pelo dicionário da língua portuguesa do software QDAMiner. Assim, as palavras mais frequentes nas peças - apresentadas na imagem acima - também foram categorizadas de acordo com sua semântica.

Optamos por levar em consideração apenas o grupo de "emoções" desse dicionário, que identifica tristeza, agressão, ansiedade, comportamento expressivo, amor, afeto e triunfo. Contudo, observamos que apenas as emoções agressão, amor e triunfo resultaram em uma presença representativa - e são os pontos que estão marcados com seta na imagem 4.

Podemos verificar, então, que os sentimentos de agressão estiveram presentes nas publicidades que se propuseram a "eliminar" cravos e espinhas de forma "rápida" ou ainda aquelas peças que abordaram tratamento de "pele". Veja um exemplo abaixo:

Asepxia Ducha é um tratamento de uso diário que controla a oleosidade e desobstrui os poros. Deixe atuar por trinta segundos para obter a tripla ação do Antiacnil-3. Formulado para atacar cravos e espinhas nas costas, peito e ombro. Asepxia é rápido (Asepxia, TV Record, 18 jun 2013).

O sentimento "amor" esteve presente nas peças que apresentaram uma narrativa marcada pela importância de relacionamentos entre família e amigos. Com esse perfil, as peças da marca Danone foram as mais recorrentes: a doiogurte Activia, que apresentava uma "Dica de amiga", e a do Danoninho, que menciona seus ingredientes - como cálcio e vitaminas - e ainda apresentava uma narrativa focada na saúde dos filhos. Já a peça sobre o iogurte Densia - da mesma marca, mas voltado para o público mais adulto - ressaltava a contribuição do produto na assimilação do cálcio no organismo, fortalecendo as pernas e melhorando a qualidade de vida das pessoas da terceira idade que, após ingerir o alimento, poderiam aproveitar o tempo com os amigos.

$\mathrm{O}$ triunfo, por sua vez, estava associado às publicidades sobre produtos para cabelos e um exemplo representativo dessa relação é a peça publicitária do xampu Tio Nacho, apresentada anteriormente, que trazia uma narrativa triunfante e vitoriosa sobre o desenvolvimento do produto.

Por último, destacamos as palavras que foram relacionadas à ciência e que podemos observar no gráfico 2. 
Figura 6 - Principais palavras relacionadas à ciência nas publicidades analisadas

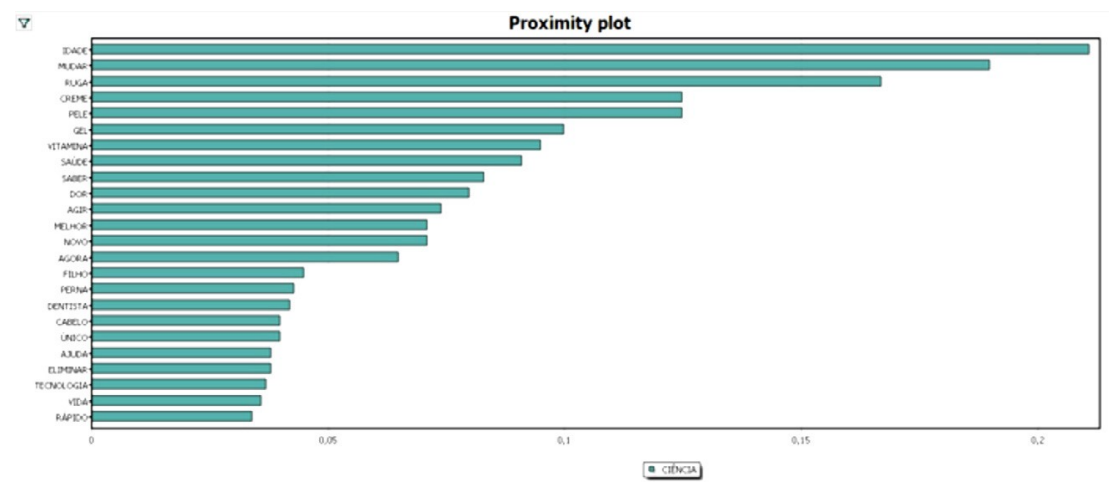

Fonte: Gráfico gerado pelo software QDAMiner

Os dados do gráfico 2 corroboram as informações obtidas pela análise de conteúdo: os produtos para a pele - cremes e géis anti-idade, usualmente - estão entre aqueles que mais fizeram uso da ciência nas suas narrativas publicitárias.

A tecnologia também esteve aliada à ciência, assim como os adjetivos melhor, novo, único e rápido, mostrando a representação de uma ciência inovadora, produtiva e diferenciada. Além disso, ressaltamos a presença de alguns verbos recorrentes, como mudar, agir, eliminar e ajudar. Esses termos são verbos de movimento, representando ações transitórias, e, ao estarem associados a assuntos científicos, demonstram o caráter transformador da ciência das publicidades.

\section{Discussão e considerações finais}

Neste artigo, discorremos sobre o perfil das publicidades veiculadas pela TV aberta brasileira que apresentaram assuntos relacionados à ciência em suas narrativas. Primeiramente, destacamos a desigualdade encontrada entre as peças publicitárias veiculadas nas emissoras. A TV Record transmitiu cerca de três quartos do total de peças incluídas em nosso corpus e, a maior parte delas, não estava presente na programação da TV Globo. Além disso, a TV Record veiculou quase todos os merchandisings analisados, o que sugere um perfil diferenciado da emissora sobre esse gênero específico e também sobre categoria televisiva de publicidade como um todo - possivelmente devido ao público diferenciado das emissoras.

De uma forma geral, os assuntos científicos estiveram presentes em quase todos os gêneros de publicidades e foram trabalhados das mais diversas formas. Houve menção direta à "pesquisa científica"; houve presença de cientistas recomendando marcas e produtos (mesmo que tenham sido poucas vezes); houve menção a nomes científicos e a nomenclatura técnica das substâncias dos 
produtos; e ainda houve animações que explicavam o funcionamento do corpo humano e a ação de remédios.

A ciência foi utilizada nas peças analisadas como um recurso publicitário para conferir legitimidade e confiança aos produtos ofertados. Assim como Rosa (2005) e Carmo (2014), consideramos que o discurso científico nas peças publicitárias gera um argumento com "efeito de verdade", pois representa uma voz de autoridade. Também em consonância com Torres (2012), observamos que o discurso científico se adaptou ao perfil publicitário, afastando-o dos seus objetivos acadêmicos de produção do conhecimento em si e tornando-se um motivador de compra.

A maioria das peças enfatizou questões estéticas e a sua narrativa foi marcada pela agressividade, esta direcionada às rugas e acnes que deveriam ser "eliminadas" e "combatidas" rapidamente com auxílio da ciência. Por outro lado, a confiança nos resultados positivos dos produtos ofertados gerou um sentimento de triunfo, enquanto que o amor esteve relacionado à melhor qualidade de vida, aos momentos em família e entre amigos que poderiam estar ao alcance dos consumidores que, efetivamente, fizessem a compra.

Observamos uma representação positiva da ciência, com ênfase nos seus benefícios, observada nas narrativas sobre produtos que apresentam resultados rápidos e práticos no dia a dia das pessoas. Essa abordagem que destaca os benefícios da atividade científica já foi observada em análises sobre a cobertura jornalística de temas de ciência o (Amorim \& Autor; Ramalho et al.), o que mostra uma semelhança - em certo grau - entre publicidades e jornalismo. Quando se fala de ciência, a principal informação a ser destacada, tanto no jornalismo como na publicidade, é a novidade e o benefício que a atividade científica traz para a população. A diferença é que, nas peças publicitárias, esse benefício é capitalizado.

Outro aspecto interessante do perfil da ciência nas publicidades analisadas foi a proximidade das questões científicas às palavras agora e rápido, assim como a associação às ideias de mudança e de agir sobre uma determinada situação - como aliviar a dor ou eliminar algo indesejado, por exemplo. Essas características dão subsídios para construir uma representação de ciência associada a uma ação mais imediata - portanto, uma ciência mais prática, operacionalizada, que atua diretamente nos e pelos produtos ofertados.

Assim, constatamos que a ciência está presente de diversas formas na programação televisiva brasileira, não só nos materiais informativos e de entretenimento (Ramalho et al; Rondelli, 2004), mas também nas publicidades. Considerando o importante papel da TV no país (Reimão, 2010; Wolton, 2006), a abordagem de assuntos científicos de maneira regular pode contribuir para que a população tenha acesso a esse tipo de informação e se aproxime da temática - mesmo que o objetivo dessas programações não seja o de fazer divulgação científica em si ou popularizar a ciência, como Torres (2012) já observou. 
Por essa razão, consideramos importante ampliar os estudos na área de ciência e TV, incluindo estudos com publicidades, para termos mais informações sobre como as questões científicas estão presentes nesse meio de comunicação tão importante para os brasileiros e esperamos ter incentivado estudos posteriores que poderão agregar mais reflexões sobre a ciência na TV brasileira.

\section{Referências}

Almeida, S.; Nascimento, P.; Quaioti, T. (2002). Quantidade e qualidade de produtos alimentícios anunciados na televisão brasileira. Revista Saúde Pública, São Paulo, 3 (36), 353-355.

Amorim, L.; Autor. Jornalismo científico: um estudo de caso de três jornais brasileiros. Revista Brasileira de Ensino de Ciência e Tecnologia, Curitiba, 1(1), 73-84, jan/abr.

Aronchi, J. (2004). Gêneros e formatos na televisão brasileira. São Paulo: Summus.

Autor; Ramalho, M. Monitoramento e capacitação em jornalismo científico: a experiência de uma rede ibero-americana. Rio de Janeiro: Museu da Vida / Casa de Oswaldo Cruz / Fiocruz: Centro Internacional de Estudios Superiores de Comunicación para América Latina (Ciespal).

Azevedo, G.; Pereira, O. (2010). Análise da publicidade das propagandas de medicamentos veiculadas em emissoras de televisão. Farmácia \& Ciência, 1(1), 3-15, ago./dez.

Bolaño, C. (2004). Mercado brasileiro de televisão. 2a edição. São Cristóvão (SE): Universidade Federal de Sergipe; São Paulo: EDUC.

Carmo, A. (2014). A dimensão probatória do discurso publicitário. Cambiassu: Estudos em Comunicação, 19 (14), 4-18.

Cashmore, E. (1998). e a televisão se fez! São Paulo: Summus.

Ferreira, A. (2009). Leitura Discursiva em Publicidade e Propaganda: uma análise da função argumentativa do interdiscurso. Ser, 1(1), 56-66.

Fialho, A.; Almeida, M. (2008). Publicidade a géneros alimentícios no meio televisivo dirigida a crianças e adolescentes em Portugal. Revista da SPCNA, 14(2), 577-65.

Grupo globo. (2017). Grupo Globo. Disponível em: <http://grupoglobo.globo.com/index.php>.

Haberkamp, C. (2013). Publicidade e consumo: a articulação entre recepção e consumo dos cosméticos anti-idade. Trabalho de Conclusão de Curso (Bacharelado em Comunicação Social) - Universidade Federal do Rio Grande do Sul, Porto Alegre.

Instituto Brasileiro de Geografia e Estatística. (2016). Acesso à internet e à televisão e posse de telefone móvel celular para uso pessoal: 2015. Rio de Janeiro.

Jacks, N.; Menezes, D.; Piedras, E. (2008). Meios e audiências: a emergência dos estudos de recepção no Brasil. Porto Alegre: Sulina.

Jacks, N.; Piedras, E. (2006). Estudos de recepção da publicidade: explorando as pesquisas da década de 1990. Comunicação, mídia e consumo. 3 (7), 113-130.

Kantar Ibope Mídia. (2016). Investimento publicitário Meios de Comunicação - Janeiro a Dezembro 2016. Disponível em: <https://www.kantaribopemedia.com/meios-de-comunicacao-janeiro-\%do\%bo-dezembro-2016/>.

Lewis, R.; Maas, S. (2007). QDA Miner 2.0: Mixed-model qualitative data analysis software. Field methods, 19(1), 87-108.

Lucas, L.; Hoff, T. (2007). Da cronobiologia aos neurocosméticos: o advento do corpo-mídia no discurso publicitário da beleza. In: Encontro Anual da Compós - Associação Nacional dos Programas de Pós-Graduação em Comunicação, 2006. Unesp-Bauru. Anais... Porto Alegre: Sulina, 93-112. 
. (2006). Da ortopedia ao controle do corpo: o discurso da saúde na publicidade. Comunicação Mídia e Consumo, 3(6), 81-104.

Mattos, S. (2010). História da televisão brasileira: uma visão econômica, social e política. Petróplis: Editora Vozes.

Melo, A.; Santana, C.; Brito, M. (2005). Imaginário feminino no consumo de cosméticos: um estudo sobre a significação das marcas de cremes faciais e o uso desses produtos para o público feminino. Monografia (Pós-Graduação em Administração) - Núcleo de PósGraduação em Administração, Universidade Federal da Bahia, Salvador.

Mídia Dados Brasil. (2017). Televisão. Disponível em: <https://dados.media/\#!/dashboards/ TELEVISION $>$.

Piedras, E. (2014). Ascensão dos estudos de recepção em publicidade: contribuições nas abordages comportamental, sociocultural e sociodiscursiva. In: JACKS, N. (Org.). Meios e audiências II: a consolidação dos estudos de recepção no Brasil (pp. 171-186). Porto Alegre: Sulina.

Ramalho, M.; Polino, C.; Autor. Do laboratório para o horário nobre: a cobertura de ciência no principal telejornal brasileiro. Journal of Science Communication, 11, 1-10.

Rede Record. (1998) Rede Record: 45 anos de história. São Paulo: Antonio Bellini Editora e Design.

Reimão, S. A televisão no Brasil - ontem e hoje. (200o). In: Reimao, S. (Org). Televisão na América Latina: sete estudos (pp. 7-10). São Bernardo do Campo: Universidade Metodista de São Paulo.

Rondelli, D. (2004). A ciência no picadeiro: Uma análise das reportagens sobre ciência no programa Fantástico. Dissertação (Mestrado em Comunicação Social) - Universidade Metodista de São Paulo (UMESP), São Paulo.

Rosa, A. (2005). Publicidade científica: um estudo do modo de organização do discurso argumentativo em revistas femininas. Dissertação (Mestrado em Letras e Lingüística) - Universidade Federal de Pernambuco (UFPE), Recife.

Torres, H. (2012). La ciencia en la televisión nacional. Análisis de los comerciales de Televisión. Dissertação (Mestrado em Sociologia) - Universidad Nacional de Colombia, Bogotá.

Trench, B. (2003). Media Studies Module. Carolina do Sul: The European Network of Science Communication Teachers.

Wolton, D. (2006). Elogio do grande público: uma teoria crítica da televisão. São Paulo: Editora Ática.

Wzorek, L. (2005). Avaliaçăo da qualidade das propagandas de medicamentos veiculadas em diferentes mídias e locais no estado do Paraná. Dissertação (Mestrado em Ciências Farmaceuticas) - Universidade Federal do Paraná, Curitiba. 
